Revisões e Reflexões

AA 


\title{
INFLEXÕES SUBALTERNAS NOS COSMOPOLITISMOS VERNACULARES
}

\author{
Sneja Gunew \\ University of British Columbia, Canadá
}

\begin{abstract}
RESU MO
O conceito sobre o termo relativamentre novo, "cosmopolitismos vernaculares", identifica as responsabilidades e os contextos globais ao mesmo tempo que reconhece que eles estão sempre enraizados e enredados em interesses locais, os quais incluem os grupos minoritários que competem dentro da nação. Este artigo examina o termo "europeu" com o objetivo de desnudar os debates revisionistas sobre o cosmopolitismo, especialmente em relação aos "cosmopolitismos vernaculares" que funcionam como uma maneira de incluir os "cosmopolitismos subalternos" por meio da desagregação do cosmopolitismo, num movimento análogo à noção de "processo democrático agnóstico" de Stuart Hall. O paradoxo da frase acima reflete o movimento duplo desses debates: no termo cunhado por Homi Bhabha o "doméstico" ou "nativo" vernacular está sempre em uma relação dialógica com a "ação a distância" do cosmopolitismo global. Exploro essa dinâmica ao focalizar os significados discrepantes de "europeu" e dos termos a ele associados. Neste artigo, meu argumento central é: os termos "oeste" e "europeu" devem ser desconstruídos para que não possam mais ser invocados, nos debates pós-coloniais, como incontestáveis categorias heurísticas como, por exemplo, o "oeste e o resto." Os novos debates sobre cosmopolitismo abrem caminho para se reconhecer, como estados-nação e como parte da União Europeia, a heterogeneidade cultural de tais entidades geopolíticas. Reconhecer o cosmopolitismo dos grupos subalternos facilita esse empreendimento e ajuda a restabelecer uma perspectiva "planetária."
\end{abstract}

\section{PALAVRAS-CHAVE}

Cosmopolitismo, diáspora, Austrália

\section{INTRODUÇÃO: COSMOPOLITISMOS VERNACULARES COMO EMPREENDIMENTOS PEDAGÓGICOS}

$\mathbf{E}_{\mathrm{m}}$ meio às novas polarizações ideológicas, estamos lutando para encontrar formas de se pensar sobre as configurações e os legados que nos remetem à creolização, à mestiçagem e ao hibridismo cotidiano de nossas relações globais. Neste artigo, argumento em favor dos cosmopolitismos das classes baixas com o objetivo de desordenar a relação 
habitual entre o cosmopolitismo e as práticas elitistas frequentemente associadas a termos tais como "cidadão do mundo". ${ }^{1}$ Essas teias de conexões cosmopolitas são, muitas vezes, mediadas por e enraizadas em um inescapável contexto local e paroquial, que tem início com um corpo disciplinado por meio de padrões viscerais e afetivos de linguagens, comidas e ritos familiares, os quais, provavelmente, incluem o lado espiritual e metafísico. Como nos lembra Sheldon Pollack, o próprio termo "vernacular" abriga noções relativas ao nativo, ao indígena e ao escravo.

Irei focalizar o amplo alcance do termo "cosmopolitismo vernacular" - com base na questão, quem é considerado europeu - oferecendo alguns exemplos do modo como o "europeísmo" circula, atualmente, com diferentes significados em vários discursos. Abordar alguns dos significados globais do termo "europeu" implica reconhecer que a Europa continua funcionando como uma metáfora imperial ou colonial que evoca modernidade, civilização e (nas palavras de Fernando Coronil) o "ser moderno." Na verdade, Neil Lazarus descreve esse termo, sucintamente, como uma categoria ideológica disfarçada de geográfica. Quando a Europa se torna sinônimo de "oeste", como por exemplo nas discussões pós-coloniais ou nas encarnações neocoloniais relativas à "guerra do terror," precisamos ser bem mais específicos sobre as versões do ocidentalismo que são, frequentemente, mobilizadas para funcionar em oposição binária a versões igualmente suspeitas do orientalismo. Por exemplo, a relativamente recente organização formada pela União Europeia (UE) poderia ser descrita como uma tentativa de se criar uma "comunidade" que produza um excesso para a nação ou que o transcenda. ${ }^{2}$ Enquanto a UE se expande, nota-se que ela passa a incluir aqueles que eram marginalizados por estarem, até então, localizados fora daquilo que é visto tradicionalmente como parte da "Europa". E, assim, percebe-se, imediatamente, a natureza híbrida do oeste e da Europa. Isso, por sua vez, provoca reverberações retroativas nas histórias coloniais, incluindo aquelas relacionadas às colônias de assentamento. O que o termo "europeu" significa e significou nesses contextos? Dubravka Ugresic, por exemplo, tem muitas coisas irônicas a dizer sobre o ímpeto mercadológico que a classifica, regularmente, como uma escritora "croata". Em todos os seus trabalhos, Ugresic mostra as dimensões daquilo que este artigo tenta evocar por meio do termo "cosmopolitismos vernaculares":

O problema da orientação na Europa decorre das fantasias de seus habitantes sobre eles mesmos e os outros. Os guias turísticos de retórica empoeirada têm tentado nos convencer de que seus países, regiões ou cidades serviram, ao longo de toda a história, de baluarte contra o Outro; o Outro que, é claro, vinha invariavelmente do leste. Como resultado, todos os habitantes da Europa preferiam se ver como parte do ocidente e não do oriente. Pertencer ao ocidente dá aos europeus a sensação de estarem do lado certo da vida.

\footnotetext{
${ }^{1}$ Conferir, por exemplo, conceitos bastante eficazes, tais como o "cosmopolitismo abjeto" de Peter Nyers, desenvolvido - em seu estudo sobre as possibilidades de agenciamento associadas aos refugiados e aos indivíduos que procuram asilo - sob a influência do conceito de seres humanos descartáveis de Giorgio Agamben. Meus agradecimentos a Nandita Sharma, por me alertar sobre esse trabalho.

${ }^{2}$ BURUMA; MARGALIT. Occidentalism: The West in the Eyes of its Enemies; BALIBAR. A Plea for an Alter-Globalising Europe; TODOROV. The New World Disorder.
} 
A outra palavra-chave das fantasias nacionais é encruzilhada. Caso não possuam nada mais, esses países, cidades e pessoas sentem que, pelo menos, estão nas junções cruciais. O baluarte e a encruzilhada são as fantasias mais amplamente preservadas pelas pessoas pequenas, no momento em que elas constroem uma imagem positiva de si mesmas. ${ }^{3}$

Em suma, meu estudo questiona se o conceito de cosmopolitismos vernaculares é capaz de nos oferecer ferramentas úteis para o ensino das imbricações do global e do local em nossos empreendimentos pedagógicos, que incluem o pós-nacional, o nacional e o intranacional como canais de reconhecimento dessas redes mais amplas de relações.

\section{A COLCHA DE RETALHOS FORMADA PELOS SERES E A MODERNIDADE}

O conceito de "oeste", conforme tem sido usado pela teoria pós-colonial(...) não possui nenhum referente crível ou coerente. Trata-se de uma categoria ideológica disfarçada de geográfica, assim como - no contexto do discurso orientalista moderno - o "islã" é uma categoria ideológica disfarçada de categoria religiosa. ${ }^{4}$

(...) o oeste é freqüentemente identificado com a Europa, com os Estados Unidos, com o pronome nós ou com aquela enigmática entidade: o ser moderno. ${ }^{5}$

As observações sobre quem pode ser considerado europeu resvalam, muitas vezes, para questões relativas à "brancura". Nos últimos anos, a crítica à "brancura" tem aumentado bastante na América do Norte e, de modo diferente, mas progressivo, nas colônias de assentamento. Um dos maiores problemas refere-se ao fato de os estudos sobre a brancura terem, de certa forma, contribuído para a reificação e não para a desagregação dos conceitos relativos ao "sujeito ocidental" e ao que constitui a "civilização" europeia/ocidental. ${ }^{6}$

A tentativa de excluir o aparente "poder epistemológico universal" da "brancura" é facilitada pelo escrutínio de termos que têm sido usados tradicionalmente para descrever as supostas contribuições da "civilização" europeia/ocidental: cosmopolitismo, racionalismo, universalismo etc. ${ }^{7}$ Desse grupo, é o "cosmopolitismo" que tem sido reordenado por aqueles que lutam contra o crescimento do absolutismo étnico e o fortalecimento dos nacionalismos em que o cosmopolitismo representa uma forma de se repensar a globalização em termos de relações intra e pós-nacionais. $\mathrm{O}$ cosmopolitismo crítico tem sido usado para reconfigurar as relações entre os nacionalismos e a globalização e para contra-atacar o crescimento das várias formas de fundamentalismo ao redor do mundo. ${ }^{8}$ No passado, termos tais como "multiculturalismo" foram usados para traçar as complexas dimensões das diferenças culturais. Porém, como o multiculturalismo foi, durante muito tempo, comumente associado ao gerenciamento estatal das diferenças, outros termos

\footnotetext{
${ }^{3}$ UGRESIC. Europe, Europe, p. 111-112.

${ }^{4}$ LAZARUS.The Fetish of "the West" in Postcolonial Theory, p. 44.

${ }^{5}$ CORONIL. Beyond Occidentalism: Toward Nonimperial Geohistorical Categories, p. 52

${ }^{6}$ Conferir a edição especial que editei do Feminist Theory (v. 8, n. 2) sobre "Rethinking Whiteness."

${ }^{7}$ WIEGMAN. Whiteness Studies and the Paradox of Particularity, p. 150.

${ }^{8}$ CHEAH; ROBBINS. Cosmopolitics: Thinking Freely Beyond the Nation; GILROY; APPIAH; APPADURAI; DERRIDA. Cosmopolitanism and Forgiveness; BRECKENRIDGE et al. Cosmopolitanism.
} 
foram descobertos e o cosmopolitismo acabou emergindo como uma possibilidade de configuração de novos paradigmas para contrabalançar a intempérie frequentemente associada à globalização. Isso remete, por exemplo, ao "Manifesto Cosmopolita" de Ulrich Beck. ${ }^{9}$ Nas palavras de Helen Gilbert e Jacqueline Lo, o "novo cosmopolitismo, ou seja, esse modelo explanatório de uma cidadania global em constante evolução, precisa se engajar a concepções mais performativas e personificadas do termo que pode ser empregado para pessoas, grupos, culturas e práticas". ${ }^{10}$

$\mathrm{Na}$ atual ordem global, quem poderia prever que binarismos comuns iriam ressurgir com tamanho ímpeto e que eles buscariam suas origens nos velhos mitos constitutivos do leste e do oeste, tais como o islamismo e o cristianismo? Além desses binarismos, encontramos reivindicações a favor do "ser moderno", que é descrito como alguém que possui acesso privilegiado à modernidade e que possui a superioridade moral de ser considerado mais civilizado e mais ético ao, por exemplo, disseminar a "democracia" por meio de cruzadas militares. Essa versão do "ser moderno" também inclui a consolidação da "interioridade", isto é, o fato de se possuir uma vida interior (em distinção ao ser "pré-moderno" que parece ser apenas uma superfície).

É possível encontrar, há séculos atrás, uma poderosa alegoria do "ser moderno": a Criatura sem nome do Dr. Frankenstein, produzida artificialmente com partes recicladas de corpos humanos, fornecidas por indivíduos que não tinham direito de decisão sobre a cessão ou venda de seus órgãos para essa finalidade. Na guerra contemporânea de insultos e retaliações sobre como as culturas devem ser identificadas, ou seja, como póscoloniais, neocoloniais ou des-colonizadas, esse texto traz a marca registrada do famoso argumento de Gayatri Spivak: ele não reproduz os axiomas do imperialismo e não está preso na reprodução do individualismo feminino (europeu). ${ }^{11}$ Muito já foi dito sobre esse romance, gostaria, porém, de descrever a maneira como a "europeização" é abordada no início do século XIX. Notamos que, naquilo que pode ser considerado como a busca pós-humana de uma versão autorizada do humano, a Criatura adquire linguagem ao ouvir, clandestinamente em seu esconderijo, as palavras da "doce árabe" Safie, que, na verdade, é turca. O texto, que transmite à Safie e à Criatura conhecimentos sobre história e relações sociais, é o Ruins of Empire, de Volney. Trata-se de um título revelador que nos catapulta para o momento presente, o qual inclui, de acordo com o resumo da Criatura, uma série de estereótipos raciais e culmina com a "descoberta do hemisfério americano", quando ambos (Safie e a Criatura) choram "por causa do destino de seus habitantes originais". ${ }^{12}$ A Criatura adquire linguagem mais rapidamente que Safie (a qual continua a manter certo sotaque, pois seu aprendizado não ocorre em território tão virgem quanto o da Criatura, ou seja, ela já possui uma outra linguagem). Como no caso do predecessor Caliban, a linguagem gera questões ontológicas na Criatura: quem sou eu? Além de referências à sua própria anomalia e monstruosidade: "Então eu sou um monstro?"13

\footnotetext{
${ }^{9}$ BECK. The Cosmopolitan Manifesto.

${ }^{10}$ GILBERT; LO. Performance and Cosmopolitics: Cross-cultural Transactions in Australasia, p. 12.

${ }^{11}$ SPIVAK. Three Women's Texts and a Critique of Imperialism, p. 316.

${ }^{12}$ SHELLEY. Frankenstein, p. 119.

${ }^{13}$ SHELLEY. Frankenstein, p. 120.
} 
Se o famoso filme de James Whale, de 1930, mostra a Criatura como uma alegoria da pobre classe trabalhadora da época da Depressão, é fácil percebê-la, hoje, em seu casebre próximo ao chalé dos De Laceys, como um subalterno abjeto excluído de toda a humanidade, ainda que, de acordo com as convenções textuais, ela consiga falar na primeira pessoa. Quanto à Safie, descobrimos que ela aprende, com sua mãe árabe e cristã, a buscar a "independência (...) proibida às mulheres seguidoras de Maomé”, e acaba escapando de seu pai - representado como um típico déspota oriental - ao fugir para um território genericamente europeu. ${ }^{14}$ A criatura, por sua vez, aprende a ser humana (ou a ser um simulacro do humano) ao adquirir linguagem e afetividade, mas ela não consegue a reciprocidade: possui sentimentos e chora, mas ninguém chora por ela. Ao ser completamente isolada e hostilizada, a Criatura jura se vingar da espécie que pode, com certeza, ser categorizada como a humanidade. Tal humanidade, porém, não é, necessária e exclusivamente, europeia.

Essa leitura é feita para mostrar que, nesse texto, o termo "Europa" é mais facilmente compreendido como uma metáfora. ${ }^{15} \mathrm{Na}$ verdade, é necessário um exame minucioso para determinar exatamente onde e em qual língua os eventos ocorrem. Por exemplo, os De Laceys falam francês, então, essa é a língua que a Criatura aprende, porém, como demonstra a carta estrutural do Capitão Walton para sua irmã na Inglaterra, o francês parece ser intercambiável pelo inglês. Nesse caso, a diferença é predominantemente de classe, pois se presume que a classe, a qual a autora Mary Shelley pertencia, tinha fácil acesso ao francês, alemão, italiano (e, certamente, ao latim). Em outras palavras, o "ser moderno" daquela época aspirava à condição de elite cosmopolita, definida por uma mobilidade relativamente simples. A palavra árabe, que como termo genérico pode incluir os turcos, era também uma categoria claramente bastante difusa. $O$ pai de Safie aparece como alguém que está encarcerado em Paris não "pelo crime que o condenou, mas sim por causa de sua religião e riqueza". ${ }^{16}$ Nessa mesma oração, o leitor também descobre que "toda Paris estava indignada." Entretanto, o Estado o persegue e arruína os De Laceys por ajudá-lo a escapar. Assim, a espantosa escalada da atual oposição binária, codificada como Cristianismo versus Islamismo, não é necessariamente reconhecida.

O exemplo apresentado por esse texto do início do século XIX revela a instabilidade histórica subjacente ao "ser moderno" e ajuda a ressaltar que: esse conceito nunca esteve consistentemente enraizado em nenhuma linguagem ou nação específica, nem se estabeleceu em algum tipo de ideia determinada sobre o que constitui a noção de "europeísmo". Conforme podemos perceber, pelo exemplo do rico pai de Safie, havia, no século XIX, certa estabilidade provisória no posicionamento de classe, que era acessível, também, aos "árabes". Porém, a versão do "ser moderno", que prevalece no presente, envolve incursões ao que constitui o (não) europeísmo - bem como a (não) brancura - e aos legados éticos e históricos a eles vinculados. A descrição dessas histórias inclui considerações sobre as tentativas de se enquadrar a diferença cultural por meio de uma variedade de termos que vão do

\footnotetext{
${ }^{14}$ SHELLEY. Frankenstein, p. 124.

${ }^{15}$ Chomsky citado por CORONIL. Beyond Occidentalism: Toward Nonimperial Geohistorical.

${ }^{16}$ SHELLEY. Frankenstein, p. 122.
} 
multiculturalismo ao transculturalismo, até atingir, progressivamente, o cosmopolitismo que é sustentado pelo orientalismo e pelo ocidentalismo. Todos podem ser descritos como dependentes de uma temática de contaminação que desestabiliza qualquer categoria mencionada, algo que talvez seja mais perceptível quando analisado nas colônias de assentamento que englobam o coração dos antigos impérios: o inapropriadamente chamado novo mundo onde o "hapa" 17 e as múltiplas alianças das misturas de raças guiam as autoetnografias, inclusive dos sujeitos indígenas. Argumentei recentemente, por exemplo, que o campo dos estudos sobre a brancura é radicalmente restaurado quando o indigenismo - e não as relações entre o branco e o negro estabelecidas pelos afro-americanos - é apresentado como o significante central da diferença. ${ }^{18}$ Assim como acontece com Safie e a Criatura, os desafortunados habitantes originais das Américas (os nativos americanos) retornam a essas discussões de maneira muito mais vigorosa do que como meras presenças assombradas.

Mas, de que forma termos tais como "europeu" ou "oeste" adquirem seus significados dentro de histórias específicas de assentamentos coloniais? Aqui, portanto, torna-se necessário retomarmos o termo multiculturalismo. ${ }^{19}$

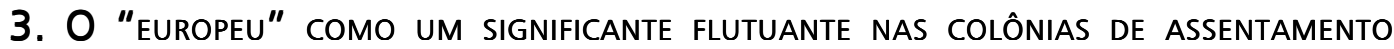

De acordo com o argumento central de meu último livro, Haunted Nations, 'o "multiculturalismo" é um termo que adquire significados muito diferentes, dependendo dos contextos locais e nacionais e das histórias por onde circula. ${ }^{20} \mathrm{O}$ mesmo pode ser dito de "europeu".

$\mathrm{Na}$ Austrália, a imediata migração do pós-guerra foi totalmente europeia no sentido geográfico, embora abrangesse muitos indivíduos procedentes do leste e do sul da Europa e não, como era mais desejável, do norte do continente. Na verdade, a diáspora da Europa estava longe de ser o fenômeno homogêneo citado, tão benevolentemente, pela ideologia que encontrei enquanto crescia. Conforme afirmei em Haunted Nations, os "europeus", incluindo meus pais e outros como eles, foram deslocados com base em uma versão da "Europa" que pude identificar, muitas décadas depois, como britânica - ou, mais precisamente, como anglo-celta, por causa de uma específica história colonial de migração (inclusive de classe) para a Austrália. Isso resultou, certamente, na extinção daquilo que é, de modo geral, designado como "Europa continental" e, consequentemente, no bloqueio do crescimento de outras línguas além do inglês.

\footnotetext{
${ }^{17}$ Nota da tradutora: De acordo com o Hawaiian Dictionary, Revised and Enlarged Edition, de Mary Kawena Pukui e Samuel H. Ebert (University of Hawaii Press, Honolulu HI, 1986), o termo hapa é usado para definir os indivíduos descendentes de etnias e raças distintas, como, por exemplo, os descendentes do cruzamento de brancos e havaianos.

${ }^{18}$ GUNEW. Rethinking Whiteness.

${ }^{19}$ Esse não é um termo que pode ser simplesmente transferido para o passado. Conferir, por exemplo, KYMLICKA. Multicultural Odysseys: Navigating the New International Politics of Diversity.

${ }^{20}$ GUNEW. Haunted Nation: The Colonial Dimensions of Multiculturalisms.
} 
Nos anos 1970, o surgimento de uma política estatal multiculturalista abre caminho para essas outras histórias, culturas e linguagens que compõem uma colônia de assentamento. É interessante notar que, nesse momento, houve também na Austrália um aumento da preocupação com o indigenismo. Mas a versão desse indigenismo contribuía frequentemente para o embate sobre quem poderia reivindicar a autoridade da primordialidade autóctone que serviu para assegurar o direito a uma específica versão do nacionalismo. Conforme nos lembra Benedict Anderson, o nacionalismo é sempre imaginário e, nessas nações colonizadas, as etnias, que apresentavam sua etnicidade como invisível e fundacional, dominavam aqueles que eram rotulados de "étnicos". Reconhece-se, cada vez mais, que as diásporas migratórias cruzaram muitas fronteiras de estados-nação e que as sociedades multiculturais são, na maior parte do mundo, uma realidade empírica. Porém, o que diferenciou o multiculturalismo da Austrália e do Canadá, sob o aspecto das colônias de assentamento, foi que, pelo menos por algum tempo e em graus variados, eles incorporaram o multiculturalismo em suas descrições e definições de nação. Em certa medida, essa retórica persuadiu e convenceu os estrangeiros que não percebiam as incrustações desse multiculturalismo em significados localizados. Ao mesmo tempo, passou a existir, cada vez mais, certa suspeita em relação a esse multiculturalismo normalizado cuja origem histórica se baseia em um aparato estatal projetado para gerenciar demografias variadas. ${ }^{21} \mathrm{Meu}$ último livro explora alguns temas associados à complexa dinâmica existente entre pós-colonialismo e multiculturalismo ${ }^{22}$ na Austrália e no Canadá, e mostra suas divergências com as generalizações das análises contemporâneas que emanam de locais tais como os Estados Unidos. Na verdade, está claro, por exemplo, que as formas usadas por alguns críticos norte-americanos para evocar o termo "europeu" remetem novamente ao registro estado-unidense de um discurso de supremacia branca que é ordenado contra uma história afro-americana de escravidão. ${ }^{23}$ De modo geral, isso está intimamente relacionado às diferentes histórias de colonização existentes entre essas colônias e os Estados Unidos.

Uma maneira de se elucidar essas diferenças é considerar a importância do indigenismo. A influente distinção, feita por Vijay Mishra e Bob Hodge, sobre o que eles consideram pós-colonialismos oposicionistas e cúmplices, surge dos debates que analisam se colônias, tais como a Austrália, a Nova Zelândia e o Canadá, estão eticamente qualificadas para se denominarem pós-coloniais, tendo em vista a contínua opressão de seus povos indígenas. Mishra e Hodge preferem reservar o termo pós-colonial para as discussões sobre os povos indígenas de países que continuam suas lutas internas contra os descendentes dos colonizadores, bem como para as diásporas migratórias que vieram depois. No Canadá,

\footnotetext{
${ }^{21}$ Isso se apresenta sob diversas formas em várias partes do mundo. Por exemplo, o livro mais recente de Will Kymlicka discorre, mais uma vez, sobre a importância para o Canadá do reconhecimento dos aspectos notáveis de uma longa história de multiculturalismo, que inclui as versões gerenciadas pelo estado.

${ }^{22}$ Conforme explica Arjun Appadurai, "o uso dessas palavras por atores políticos e suas audiências talvez esteja subordinado a vários conjuntos distintos de convenções contextuais que intermedeiam suas traduções para a política pública" (APPADURAI. Modernity at Large: Cultural Dimensions of Globalization, p. 36).

${ }^{23}$ GORDON; NEWFIELD. Mapping Multiculturalism.
} 
Bonita Lawrence e Enakshi Dua desenvolveram e ampliaram argumentos semelhantes. Nos debates contemporâneos sobre a cidadania e sobre a possibilidade de a Austrália se tornar uma república independente da monarquia britânica, as bases, sob as quais são conduzidas essas discussões, estão recheadas de histórias antigas que remetem de volta a um específico legado de colonização. ${ }^{24} \mathrm{O}$ que talvez não tenha sido facilmente percebido é que o próprio multiculturalismo australiano pode ser analisado produtivamente como uma manifestação idiossincrática dessa história colonial ${ }^{25}$ (e não como uma renúncia a ela). Enquanto analistas de fora da Austrália foram persuadidos de que essa descrição do país como uma nação cultural foi um movimento planejado para apagar as reivindicações e histórias dos povos indígenas, pode-se argumentar, também, que eventos recentes, relativos a candidatos a asilo, têm revelado as fissuras dessa retórica e demonstrado que, mesmo nos anos 1980, nunca houve nenhum comprometimento amplo ou substancial com essa retórica do multiculturalismo. Reafirmo, portanto, que, nos discursos da Austrália, "europeu" continua a significar anglo-celta. ${ }^{26}$

\section{QUem PODE SER CONSIDERADO EUROPEU?}

Nos relatos australianos sobre cidadania e nação, aqueles estruturalmente classificados como "outros" - ou seja, os outros indígenas e multiculturais que também possuem uma desconhecida história mútua - são frequentemente eclipsados. Enquanto as imbricações referentes à "brancura" e ao "aborígine" ou à questão do "branco aborígine"27 foram traçadas de acordo com algumas de suas complexidades, a história dos aborígines e dos colonizadores que não são anglo-celtas ainda tem de ser sistematicamente coletada e analisada. ${ }^{28}$ Parece, portanto, haver aqui uma batalha interessante sobre quem pode reivindicar "nossos nativos" nos debates conduzidos com base na questão "quem decide corretamente", ou seja quem "tem o direito" ou é capaz de legislar em favor dos interesses dos "nativos". ${ }^{29}$

Conforme afirma Avtar Brah, não há nada autoevidente sobre a racialização e, além disso, grupos distintos são historicamente racializados de maneira diferenciada.$^{30}$ Roxanne $\mathrm{Ng}$ explica que, no contexto canadense:

\footnotetext{
${ }^{24} \mathrm{O}$ que tem sido chamado de " negócio inacabado" com os aborígines australianos continua a emergir na esteira das decisões, referentes a Mabo e Wik, proferidas pela Alta Corte, que reconheceram os direitos dos nativos (PERRIN. In the Wake of Terra Nullius; BARTLETT. The Mabo Decision), e do relatório subsequente sobre as "gerações roubadas" (a tragédia das crianças aborígines afastadas de suas famílias). ${ }^{25}$ Essa é também a linha seguida por Himani Bannerji em sua crítica ao multiculturalismo canadense como uma herança direta da luta colonial entre ingleses e franceses.

${ }^{26}$ Conferir também English and the Discourses of Colonialism (1998), especialmente o último capítulo, de Alistair Pennycook.

${ }^{27}$ McLEAN. White Aborigines: Identity Politics in Australian Art.

${ }^{28}$ Esse tópico tem sido explorado na ficção canadense, como, por exemplo, em Disappearing Moon Cafe, de SKY Lee, no qual são representadas as relações entre as nações pioneiras e os chineses. Recentemente, tais questões também têm sido abordadas nos materiais australianos, confira o trabalho de Peta Stephenson e Helen Gilbert e o trabalho de Jacqueline Lo sobre o cosmopolitismo e o teatro australiano.

${ }^{29}$ BROWN. Who Owns Native Culture?

${ }^{30}$ BRAH. Cartographies of Diaspora: Contesting Identities, p. 228.
} 
Enquanto, hoje, o racismo é encontrado em práticas discriminatórias dirigidas principalmente a pessoas de cor (como, por exemplo, os negros, sul-asiáticos e povos nativos), não foi sempre que a cor da pele e as outras diferenças físicas explícitas funcionaram como critérios de determinação das distinções raciais. O racismo dirigido aos acadianos pelos escoceses e irlandeses não é menos repugnante do que o racismo dirigido, atualmente, aos povos nativos e às minorias étnicas e raciais. ${ }^{31}$

Os canadenses ucranianos, por exemplo, eram percebidos, inicialmente, como "negros", já que eles não eram considerados parte do eixo europeu inglês-francês. ${ }^{32} \mathrm{~A}$ escritora canadense acrescenta:

Talvez eu seja européia, mas que tipo de européia? Diria que os ucranianos não são europeus da Europa. Nunca tivemos um Renascimento, uma Reforma ou Revolução Industrial. Nunca falamos o francês. Não moramos em cidades. (Os judeus e os poloneses eram os europeus do nosso meio) (...) Portanto, se querem me acusar de eurocentrismo, é preciso ser mais específico. ${ }^{33}$

$\mathrm{Na}$ Austrália ocorre uma história semelhante, ou seja, os europeus do sul e do leste são considerados "negros", ${ }^{34}$ enquanto os europeus do ocidente (especialmente do norte) foram integrados de forma relativamente rápida. Descobrir essas outras histórias que são representadas e reconhecidas como uma parte intrínseca da cultura literária australiana continua a ser uma batalha árdua. Outro campo fértil de investigação é descobrir o que configura o "branco", a "Europa" ou o "ocidente" na Austrália. Muitas vezes, nas críticas pós-coloniais, grupos de imigrantes europeus são homogeneizados e transformados em sinônimo de uma "brancura" naturalizada ou de vários imperialismos. Ao mesmo tempo, nações específicas ou grupos localizados dentro da Europa tiveram histórias muito diferentes sobre a questão do colonialismo e do imperialismo. Entretanto, no domínio da teoria pós-colonial anglófona, europeus e ocidentais costumam, de fato, converterse diretamente em ingleses ou britânicos. Para um australiano, por exemplo, há um momento revelador na coleção de Vasta e Castle, The Teeth Are Smiling: The Persistence of Racism in Multicultural Australia, quando Kalpana Ram, um acadêmico australiano sul-asiático, analisa o termo $\mathrm{NESB}^{35}$ e sugere o seguinte: "Temos, por um lado, o inglês e a literatura inglesa celebrados como a língua dos britânicos e, cada vez mais, da identidade ocidental. Por outro lado, os imigrantes pós-coloniais são caracterizados em oposição ao conhecimento do inglês." ${ }^{6}$ Para imigrantes pós-coloniais que, tais como

\footnotetext{
${ }^{31}$ NG. Sexism, Racism and Canadian Nationalis, p. 207.

${ }^{32}$ No caso canadense, o "inglês" inclui, ainda que inicialmente, os escoceses, mas não os irlandeses. Conferir DRIEDGER. Ethnic Canada: Identities and Inequalities.

${ }^{33}$ Essas especulações permeiam também seu relato sobre a viagem pela Europa Oriental nos anos oitenta, antes da queda do império soviético. Observe, em especial, a seção "Where does Europe end?" (KOSTASH. Bloodlines: A Journey in Eastern Europe.)

${ }^{34}$ GUNEW. Framing Marginality: Multicultural Literary Studies.

${ }^{35} \mathrm{O}$ termo NESB (non-English-speaking-background, ou seja, aqueles cujos antepassados não falavam inglês) é próprio do contexto australiano e aparece em muitos documentos oficiais.

${ }^{36}$ RAM. Liberal Multiculturalism's "NESB Women”: A South Asian Post-colonial Feminist Perspective on the Liberal Impoverishment of "Difference", p. 140. (Ênfase minha)
} 
Ram, sustentam o legado de uma educação britânica colonial, isso constitui um tipo de anomalia. Porém, para os imigrantes, que localizam sua ancestralidade em culturas e línguas europeias diferentes do inglês, estabelece-se um outro tipo de absurdo quando o "europeu", considerado sinônimo de britânico, exclui a Europa continental. Consequentemente, o não inglês se torna não europeu e não ocidental. ${ }^{37}$ Conforme se pode ver pelos comentários de Francesco Loriggio sobre os imigrantes sul-europeus, ecos dessa situação ocorrem também no Canadá: "Era um 'imperialismo dos sem poder', 'dos pobres' (...) os quais tinham como objetivo a sobrevivência e não a sustentação da Carga do Homem Branco. Para eles a Europa era provavelmente uma ideia mais abstrata do que a América" ${ }^{38}$ Ainda assim, é preciso ter em mente a afirmação da escritora e crítica canadense Dionne Brand, segundo a qual a categoria da "brancura" apresenta, ao longo do tempo, certa elasticidade, mas apenas para alguns:

Podem entrar nessa categoria não apenas aqueles que pertencem às chamadas nações fundadoras - os ingleses e os franceses - mas também europeus de outras nacionalidades, tais como os alemães e os ucranianos. Sua força e flexibilidade permitem o controle de disputas interétnicas (...) sem lacerar o tecido básico dos direitos dos brancos. ${ }^{39}$

Stephen Castles fala de uma perspectiva diferente, localizada na política da União Europeia, sobre uma "crescente diversidade cultural [a qual] (...) se alimenta de um pânico moral que representa o 'Forte Europeu' sob a ameaça de imprevisíveis influxos do leste e do sul, que evocam as 'hordas de mongóis' de um passado remoto". ${ }^{40} \mathrm{O}$ estudo do cientista político húngaro Lásló Kürti, sobre as tensões contemporâneas entre a Europa “ocidental", "central” e "oriental”, também revela que esse é um projeto altamente ideológico. ${ }^{41}$ É essa complexidade que é tão bem capturada pela escritora Dubravka Ugresic, na sua recente coleção significativamente intitulada Nobody's Home. O texto de Ugresic ilumina, precisamente, as posições enunciativas daqueles que exercitam, de baixo, um cosmopolitismo vernacular. Ressoa de modo semelhante, na Austrália, o trabalho de Antigone Kefalá. Em certa medida, ambos os escritores ecoam o exemplo polifônico do exílio que ficou famoso com o trabalho de Edward Said. Em outras palavras, dentro da própria Europa, analistas políticos e culturais não seriam tão rápidos em homogeneizar o "europeu", muito menos em percebê-lo como britânico. Mas, nas colônias identificadas com o inglês, parece haver uma tendência clara para se adotar uma atitude totalitária, segundo a qual a fronteira separa o inglês (até mesmo o britânico) e o resto, e não os europeus (ou ocidentais) e o resto. O projeto de se traçar uma história e um discurso de

\footnotetext{
${ }^{37}$ Uma outra abordagem do arraigado monoculturalismo e monolinguismo australiano é a coleção Translating Lives de Mary Besmeres e Anna Wierzbicka. Conferir, em especial, a introdução desse volume. ${ }^{38}$ LORIGGIO. Social Pluralism: and Literary History: The Literature of the Italian Emigration, p. 13.

${ }^{39}$ BRAND. Bread Out of Stone, p. 174. Conferir também o importante estudo de Daniel Coleman, White Civility: The Literary Project of English Canada.

${ }^{40}$ CASTLES.The Racisms of Globalization, p. 36.

${ }^{41}$ KÜRTI. Globalisation and the Discourse of Otherness in the New Eastern and Central Europe, p. 31. Para as respostas bastante diferentes de dois escritores, sobre essa questão, conferir Café Europa (1996), de Slavenka Drakulic e "The New Nomads" (1999), de Eva Hoffman.
} 
supremacia branca na Austrália reforça o reconhecimento de que a "brancura" e o "europeísmo" não são condições estabelecidas e de que as dimensões históricas e coloniais específicas dos termos (inclusive relativas às diferenças) precisam ser descobertas. ${ }^{42}$ No Canadá, a separação fundacional entre os canadenses ingleses e franceses complica essa questão de maneira distinta. Devido à presença da tradição francesa no Canadá, é muito mais difícil passar do europeu para o inglês ou seu equivalente britânico. Para ser mais precisa, deve-se ter em mente que o "europeu" também possui uma história colonial muito específica no Canadá, como tem demonstrado, entre outras, Himain Bannerji. ${ }^{43}$ De certa forma, porém, essas discussões sobre a diferença cultural como algo associado ao multiculturalismo são, atualmente, ofuscadas pelos debates sobre o cosmopolitismo e o ocidentalismo.

\section{O COSMOPOLITISMO EM RELAÇÃO AO OCIDENTALISMO}

Antes do dia 11 de setembro, houve, nas discussões pós-coloniais, uma tendência crescente de evocar o "europeu" ou o "ocidental" como se fossem termos associados aos antigos imperialismos e distantes de suas próprias histórias e divisões internas. ${ }^{44}$ É, portanto, bastante útil encontrar a descrição de Neil Lazarus citada acima. Lazarus sugere que o ocidentalismo é utilizado, cada vez mais, numa oposição binária, não tanto em relação ao orientalismo, mas sim em relação ao Islã, o qual ele também descreve como uma categoria ideológica mascarada de categoria religiosa. Os interesses são aqueles relativos às demandas da "modernidade". ${ }^{45}$ Lazarus também pergunta, por exemplo, qual trabalho analítico é feito em relação a termos, tais como "branco", "ocidental" ou "europeu", nos escritos de críticos pós-coloniais que estão tentando reconhecer as histórias e políticas exteriores aos imperialismos europeus. Sua resposta é: nesses estudos, tais termos são frequentemente invocados de forma culturalista e funcionam como um fetiche para encobrir as histórias materiais e os mecanismos de capitalismos específicos. Ao operar nessa forma culturalista reificada, eles são monumentalizados em sistemas ou estruturas inescapáveis que contaminam a "razão", a modernidade etc. O resultado disso é que, ironicamente, deixa-se pouco ou nenhum espaço para o agenciamento dos "não ocidentais".

O ensaio de Fernando Coronil, "Beyond Occidentalism," ilumina, ainda mais, os significados desse termo específico. Ele argumenta que, "O ocidentalismo(...) é, portanto, não o reverso de orientalismo, mas a condição de sua possibilidade". ${ }^{46}$ Coronil ainda sugere as seguintes definições:

\footnotetext{
${ }^{42}$ Em relação aos debates sobre o branco na Austrália, conferir MORETON-ROBINSON. Whitening Race: Essays in Social and Cultural Criticism.

${ }^{43}$ BANNERJI. The Dark Side of the Nation: Essays on Multiculturalism, Nationalism and Gender.

${ }^{44}$ CHAKRABARTY. Provincializing Europe: Postcolonial Thought and Historical Difference.

${ }^{45}$ LAZARUS. The Fetish of "the West" in Postcolonial Theory, p. 45.

${ }^{46}$ CORONIL. Beyond Occidentalism: Toward Nonimperial Geohistorical Categories, p. 53.
} 
Para desafiar o orientalismo (... )é preciso desordenar o ocidentalismo, visto como estilo de representação que produz concepções hierárquicas e polarizadas do Oeste e de seus Outros, transformando-os em figuras centrais dos relatos de histórias locais e globais. (...) quando digo "ocidentalismo" refiro-me ao conjunto de práticas representacionais que participam das produções do mundo, as quais (1) separam os componentes do mundo em unidades delimitadas; (2) desagregam suas histórias relacionais; (3) transformam a diferença em hierarquia; (4) naturalizam essas representações; e, assim, interveem, ainda que não intencionalmente, na reprodução das assimétricas relações de poder existentes. ${ }^{47}$

Em vez de perceber o ocidentalismo como algo que, em oposição ao orientalismo, incorpora a modernidade, Coronil (ecoando o argumento central de Edward Said) levanta uma questão importante, pois, na verdade, "a preocupação do oeste com a alteridade pode ser vista como constitutiva da própria modernidade". ${ }^{48}$

Para atender às minhas próprias crescentes frustrações, ${ }^{49}$ há o ponto de vista bastante útil, de Alistair Bonnett, sobre a "ideia do oeste," o qual, assim como o trabalho de Lazarus, é uma resposta parcial à forma autoexplicativa que o termo adquire de maneira indiscriminada na crítica pós-colonial em geral. Ao analisar o termo historicamente ele, assim como Coronil, percebe as formas de modernidade ocidentais e não ocidentais como sendo mutuamente constitutivas. ${ }^{50}$ Bonnett examina as conexões relativas aos debates extremamente raciais da "crise branca" e lembra que: "Enquanto a brancura pode ser apenas copiada (...) é possível tomar emprestado o 'ocidentalismo' e adotá-lo." ${ }_{1}$ Ele afirma também que enquanto o termo "oeste" remove, em certa medida, as referências explícitas relativas às formas de racialização, essas permanecem codificadas dentro do referido termo. ${ }^{52}$ Para Bonnett:

Nos últimos trinta anos, a apropriação neoliberal da ideia do oeste trouxe certo empobrecimento intelectual ao conceito. Ele se tornou um modelo muito particular, associado a práticas econômicas específicas (tais como a privatização, o trabalho e a flexibilidade do mercado de capitais) que são impostas militarmente e globalmente..$^{53}$

Deixem-me relatar aqui um fato curioso. Compareci recentemente a conferências em Budapeste e Sofia, onde parte da reinvenção do nacionalismo pós-soviético compreende tanto a aliança com a União Europeia (UE), quanto uma tentativa de remodelar certo europeísmo imaginário que incluiria esses novos membros. No caso da Bulgária isso é muito recente, pois o país ingressou na organização em 2007 e acabou de vivenciar suas primeiras eleições para as 18 cadeiras da UE. O que encontrei em minha breve visita? Nos dois lugares, Budapeste e Sofia, encontrei, com certeza, uma penetrante

\footnotetext{
${ }^{47}$ CORONIL. Beyond Occidentalism: Toward Nonimperial Geohistorical Categories, p. 57.

${ }^{48}$ CORONIL. Beyond Occidentalism: Toward Nonimperial Geohistorical Categories, p. 78.

${ }^{49}$ Refiro-me aqui a meu argumento em Haunted Nations, onde afirmo que "europeu" e "branco" adquirem significados dentro de histórias específicas de colonização.

${ }^{50}$ BONNETT. The Idea of the West: Culture, Politics and History, p. 7.

${ }^{51}$ BONNETT. The Idea of the West: Culture, Politics and History ,p, 27.

${ }^{52}$ BONNETT. The Idea of the West: Culture, Politics and History, p. 34.

${ }^{53}$ BONNETT. The Idea of the West: Culture, Politics And History, p. 139.
} 
hostilidade ao passado marxista e, consequentemente, à teoria marxista. Isso não implica, é claro, que os legados da teoria marxista tivessem desaparecido, eles estavam simplesmente camuflados pela necessidade de novas estruturas analíticas, as quais incluíam (como era esperado) certa autoconsciência em relação ao que significa ser europeu. No aeroporto de Sofia, havia um livro fino de Bojdar Dimitrov, proeminentemente exposto, cujo título, Bulgarians: The First Europeans, remete a determinados sinais referentes às demandas fundacionais. Em minha visita ao Museu Nacional de História de Sofia, notei, com interesse, que quinhentos anos do regime otomano tinham sido virtualmente apagados. Em outras palavras, uma fachada ideológica está sendo construída tão rapidamente quanto os novos prédios e empreendimentos que predominam em ambas as cidades e que as estão transformando em imensos canteiros de obras. Quem está financiando esses dois tipos de construção? Em Sofia, circula uma atraente teoria anunciando que os monopólios do antigo estado foram dominados pelos caudilhos da máfia local e que o ingresso da Bulgária na UE foi saudado, por um importante oficial, como o cavalo de Troia dos grandes interesses da máfia russa. Em Budapeste, um encontro de feministas do Leste Europeu defendeu a ideia de que as ONGs de mulheres estavam sendo financiadas por empresas tais como a Fundação Macarthur e, consequentemente, sendo usadas (mais uma vez) como verdadeiros cavalos de Troia a serviço dos interesses do imperialismo norte-americano. Essas são, também, manifestações da globalização disfarçadas de crime organizado. Elas, certamente, se conectam de diversas maneiras com os grupos diaspóricos que realizam suas alianças étnicas por meio de laços com a terra natal, os quais funcionam, de todas as formas, como filamentos que ligam, por exemplo, o leste da Europa a grupos (interesses e investimentos) no Canadá, na Austrália, nos Estados Unidos etc.

É em oposição a esses sombrios relatos de globalização que o Cosmopolitanism: Ethics in a World of Strangers, de Kwame Anthony Appiah, apresenta seu apelo por um cosmopolitismo que englobe a contaminação e a falibilidade, ou seja, mais precisamente, por algo contrário ao estabelecimento das antigas alegações de verdade associadas à subjetividade e modernidade europeia/ocidental. $\mathrm{O}$ tropo da contaminação, apresentado por Appiah, sugere uma genealogia literária que evoca, novamente, uma fértil sensibilidade gótica, ao nos conectar ao Drácula e à vingança vampírica do subalterno das margens da Europa. Trata-se de um sistema figurativo que adquire significado instantaneamente por meio da onipresença contemporânea da epidemia de AIDS/HIV. Nessas manifestações ficcionais, o passado de Drácula, apresentado como um destemido conquistador dos turcos, ${ }^{54}$ é deslocado por meio de suas vorazes incursões ao coração da Europa - ainda que, curiosamente, o próprio fato de ele ter emigrado para a Inglaterra sirva para demonstrar a validade das ambições desse país para ser considerado parte do coração europeu. É preciso lembrar que na versão de Bram Stoker, o mediador, que identifica a ascendência e a vulnerabilidade de Drácula, é o holandês Van Helsing, uma curiosa mistura de racionalismo científico e superstição folclórica. Porém, meu modelo aqui é o romance recente do australiano Christos Tsiolkas, Dead Europe. O título é revelador e, de certa forma, funciona como uma prescrição: o desejo ardente de que a

\footnotetext{
${ }^{54}$ Essa história é também o tema principal da maravilhosa reescrita de Elizabeth Kostova sobre o Drácula em The Historian.
} 
"Europa" seja morta, para que sua presença e história deixem de assombrar, especialmente, as relações diaspóricas. Nesse texto perturbador, o narrador, um jovem greco-australiano, vivencia o conhecido rito de passagem representado pela viagem de volta à antiga cultura - no caso, a Europa como um todo - quando descobre um antissemitismo decisivo, que é compreendido por ele como algo que definiu profundamente sua formação, na Austrália, como um "homem, queer e étnico". Conforme mostra a passagem abaixo, enquanto percebe os efeitos corrosivos do antissemitismo, ele também descobre que não conseguirá se libertar desse legado contumaz:

No meu tempo em Veneza eu não assisti ao pôr - do- sol do Bar do Harry, eu não visitei o Guggenheim, eu não tomei chá em um palazzo ou fui de barco para o Lidô. Eu não alimentei os pombos na Praça São Marco, nem viajei de gôndola. Eu não comi mariscos em um restaurante com vista para o Grande Canal, eu não pisei dentro de nenhuma basílica ou catedral. Eu não vi nenhuma grandiosa pintura de Titian e Tiepolo. Pelo contrário, eu visitei o gueto e bebi café no Café Beirute. Eu vi suásticas lavadas pela chuva. Examinei o rosto lastimável de um homem desesperado, vi a miséria infinita de seus olhos e vi, sim, uma vingança eterna e extenuante. O ódio nos seus olhos era feroz e passional. Eles queriam algo de mim e não prometiam nenhum perdão. Eu queria esquecer aqueles olhos, nunca mais olhar para eles novamente. Por um segundo louco e apavorante - juro foi apenas um segundo que passou, pois, eu o afastei deliberada e imediatamente - desejei que nenhum judeu jamais tivesse caminhado sobre a face desta terra. ${ }^{55}$

O narrador se metamorfoseia em um vampiro vingativo, ou seja, em uma figura retaliatória que se alimenta da culpa colonial e imperial europeia. Porém, percebe-se paulatinamente que não há nenhuma qualidade redentora em seus violentes assassinatos, salvo o fato de seus excessos esclarecerem os excessos irracionais originários do legado do antissemitismo europeu. ${ }^{56} \mathrm{O}$ texto torna-se ainda mais complicado pelo fato de o narrador ser queer e de haver um inquietante elemento homoerótico que caracteriza toda a violência. Por um lado, a história de Tsiolkas pode ser vista como uma alegoria altamente moralista e, na verdade, essas características também foram rastreadas por críticos culturais que analisaram a figura do vampiro de modo geral. ${ }^{57}$ Mas, por outro lado, o texto mostra também as horríveis possibilidades distópicas que ocorrem quando a culpa cultural é transmitida de geração para geração e fertilizada pelas atrocidades que caracterizaram a colonização do chamado novo mundo. ${ }^{58} \mathrm{O}$ romance de Tsiolkas (e seu outro trabalho) traça ligações claras entre o tratamento dado aos povos indígenas e as histórias racistas que os colonizadores de assentamento importaram e passaram a representar nas novas terras. Tsiolkas também não isenta os imigrantes posteriores de tudo o que eles são capazes de revelar em suas próprias histórias de racismo e opressão nas colônias de assentamento.

\footnotetext{
${ }^{55}$ TSIOLKAS. Dead Europe, p. 158.

${ }^{56}$ Sobre essa questão, confira a análise do livro feita por Robert Manne.

${ }^{57}$ GELDER. Reading the Vampire. Conferir também o importante trabalho do videoartista e crítico de cinema libanês Jalal Toufic. Meus agradecimentos a Mireille Astore por me apresentar sua obra.

${ }^{58}$ Talvez seja interessante analisar esse trabalho com base nos estudos recentes sobre luto e melancolia (The Melancholy of Race (2001), de Anling Cheng, por exemplo) e também sobre a "transmissão de afeto" (BRENNAN. The Transmission of Affect) relacionada à vergonha intergeracional.
} 
Isso é também uma configuração do novo cosmopolitismo crítico (reescrito a partir das margens), no qual a contaminação não é necessariamente um processo benigno que leva a uma maior tolerância. O legado vampírico de Tsiolkas cria um forte contraste com o tipo de modelo de contaminação benevolente, criado por Appiah em sua celebração do cosmopolitismo. Celebração que é, de alguma forma, uma reminiscência do cosmopolitismo elitista dos textos de Mary Shelley. Mas, a "Europa morta", representada no romance de Tsiolkas, é também aquela em que a vingança do leste é perpetrada no oeste ou no coração da Europa, de um modo que relembra algumas das ideologias associadas ao romance de Bram Stoker. A imagem do conde Drácula comprando bens imobiliários e infectando a flor da feminilidade inglesa com o veneno/remédio de seu sangue (oferecendo vida eterna, desde que o indivíduo se torne membro de sua tribo) é obviamente transformada, com facilidade, em várias alegorias (como, por exemplo, a do absolutismo étnico). Argumentou-se que o irlandês Bram Stoker estava acusando tardiamente a história colonial britânica, segundo a qual a Irlanda é considerada a primeira colônia da Grã-Bretanha. É interessante notar que esse texto, assim como o de Tsiolkas, também evoca uma religiosidade profundamente estabelecida, embora, teoricamente, ambos façam referência a domínios opostos: o anticristo, a danação etc. Dead Europe termina com a mãe do protagonista de volta à Austrália, chorando do lado de fora da igreja que tinha sido seu refúgio anterior, em uma cena que retrata a maneira como, há bastante tempo, as igrejas "étnicas" têm oferecido conforto para as comunidades diaspóricas. Sua excomunhão ocorre porque ela assume a responsabilidade pela importação dos preconceitos e racismos do "velho" para o "novo continente". E isso significa que, agora, ela está entre os condenados.

A diferença religiosa pode ou não ser uma ideologia política (para usar os termos de Neil Lazarus) disfarçada de religiosa. O que realmente sabemos é: o cosmopolitismo religioso fazia parte dos modelos que funcionavam na virada do século passado - no qual se celebrava o cosmopolitismo do Islã (por exemplo, no Império Otomano ou pelos Mughals da Índia) - e, consequentemente, sustentava os movimentos de natureza panreligiosa, tais como a teosofia. ${ }^{59}$ Para aqueles de nós, educados em um secularismo agressivo, é particularmente terrível testemunhar esses realinhamentos religiosos. Sendo assim, procuramos, um tanto quanto desesperadamente, relembrar que eles podem coexistir com as noções de tolerância cosmopolita, bem como com seus opostos (pois, precisamos nos recordar também de que os fundamentalismos possuem suas dimensões cosmopolitas).

O que está em questão nesses debates cosmopolitas? Nas palavras de Steven Vertovec e Robin Cohen, trata-se de uma tentativa de se mapear "os interesses sobrepostos de uma política pós-identitária e não comunitária de públicos heterogêneos ou híbridos com o fim de desafiar noções convencionais de pertencimento, identidade e cidadania”. Vertovec e Cohen oferecem várias categorias de significação para o termo cosmopolitismo: "(a) uma condição sociocultural; (b) um tipo de filosofia ou visão de mundo; (c) um projeto político direcionado para a construção de instituições transnacionais; (d) um projeto político para reconhecer as identidades múltiplas; (e) uma orientação ou atitude

\footnotetext{
${ }^{59}$ POLLOCK. Cosmopolitan and Vernacular in History; VERTOVEC; COHEN. Conceiving Cosmopolitanism: Theory, Context, and Practice, p. 15.
} 
comportamental; e/ou (f) um tipo de prática ou competência". ${ }^{60}$ No entanto, precisamos lembrar que parte da crítica tradicional do cosmopolitismo inclui a advertência de Brennan, segundo a qual "esse é um discurso do universal que é inerentemente local" ${ }^{61}$ E reivindicar o universalismo é, certamente, sempre um lance suspeito. Portanto, fazemos bem em seguir a sugestão de Ernesto Laclau:

Se a democracia é possível, é porque o universal não possui nenhum corpo essencial e nenhum conteúdo essencial; pelo contrário, grupos distintos competem entre si mesmos para oferecer, temporariamente, aos seus particularismos, uma função de representação universal. ${ }^{62}$

Reivindicar o universalismo em nome de um grupo ou de uma cultura particular é sempre um processo de busca de poder ideológico. Trata-se de uma outra versão do espectro do oeste, identificado por Lazarus e outros como obliterador da diferença (e, portanto, do agenciamento). Isso reproduz infinitamente a culpa colonial branca e a instala de volta em uma história bem organizada de opressão e colonialismo, a qual não deixa nenhum espaço para o agenciamento alternativo. Em resposta a essas questões, gostaria de sugerir que talvez seja útil rompermos com o alcance global do cosmopolitismo para que, assim, ele revele suas contingências históricas, diferenças internas e modernidades discrepantes.

Em seu recente livro, Visceral Cosmopolitanism, Mica Nava aborda, por exemplo, as formas segundo as quais, durante a primeira metade do século $\mathrm{XX}$, as mulheres consumidoras do Reino Unido exibiam um cosmopolitismo cotidiano por meio de seus desejos particulares por mercadorias, bem como de seus relacionamentos emocionais com os soldados negros norte-americanos e de outros tipos de relações inter-raciais. Pode-se dizer (de maneira bastante simplificada) que sua questão é: ao engendrar noções comuns de colonialismo e orientalismo, um antropólogo cultural ou sociólogo/historiador pode produzir uma imagem diferente das relações coloniais e inter-raciais daquele período. Aprendi, com Nava, a prestar atenção às subjacências viscerais do cosmopolitismo cotidiano durante seu funcionamento nas atuais relações globais.

\section{COSMOPOLITISMO VERNACULAR}

Em sua crítica ao cosmopolitismo, Tim Brennan informa que:

Seu encanto dissimulado é mais poderoso quando, em um deslocamento duplo, seu sentido político é revelado em formas culturais. Caracteristicamente, o cosmopolitismo constrói utopias políticas em disfarces estéticos ou éticos para que, assim, elas possam interpretar, de modo mais eficaz, aquilo que surge, frequentemente e sob escrutínio, como sendo, enfim, o papel econômico. ${ }^{63}$

Mas, e se, seguindo o exemplo de Nava, nós desordenarmos o cosmopolitismo ao vinculálo a um qualificador impossível? O conceito de cosmopolitismo vernacular identifica as

\footnotetext{
${ }^{60}$ VERTOVEC; COHEN. Conceiving Cosmopolitanism: Theory, Context, and Practice, p. 9.

${ }^{61}$ BRENNAN. The Transmission of Affect, p. 81.

${ }^{62}$ LACLAU. Universalism, Particularism and the Question of Identity, p. 367. (Ênfase minha)

${ }^{63}$ BRENNAN. Cosmopolitanism and Internationalism, p. 81.
} 
responsabilidades e os contextos globais, ao mesmo tempo que reconhece que eles estão sempre enraizados em interesses locais e são por eles permeados. ${ }^{64} \mathrm{O}$ paradoxo dessa frase reflete o movimento duplo desses debates. Sheldon Pollock observa que ao incluir o mundo privilegiado da pólis grega e da verna romana, ou daqueles que nasceram escravos, o termo torna-se inerentemente contraditório. ${ }^{65}$ Mas esse é, precisamente, o seu encanto. ${ }^{66}$ Em uma frase (possivelmente) cunhada por Homi Bhabha, o conceito tenta abarcar o "crescente abismo global entre a cidadania política, ainda largamente negociada nos termos do 'nacional' e do estadismo, e a cidadania cultural que é frequentemente transnacional, diásporica, híbrida e centrada na comunidade". ${ }^{67}$ Bhabha também associa esse conceito às minorias que não desejam necessariamente reivindicar primazia e cujo impulso definidor é aquele da tradução, através de culturas, em uma economia marcada mais pela iteração do que pela teleologia. ${ }^{68}$ Trata-se de uma direção seguida também por Paul Gilroy em seu anseio por um cosmopolitismo que englobe uma nova consciência planetária, cujas raízes ele localiza no texto satírico escrito por Montesquieu, no século XVIII, Persian Letters. ${ }^{69}$ As modernidades discrepantes são os contextos gerais e o cosmopolitismo vernacular $^{70}$ é a direção desse modelo, o qual inclui os marginalizados e miseráveis da terra.

É em relação a essa última frase que o trabalho de Peter Nyers sobre "cosmopolitismo abjeto" torna-se interessante. Nyers define esse conceito da seguinte maneira: "O cosmopolitismo abjeto não visa um patamar mais alto, tanto quanto visa se refugiar dentro de aparatos e tecnologias de exclusão a fim de dilacerar as rotinas administrativas, as percepções do dia a dia e as construções da normalidade."71

Deve haver formas de se organizar, por exemplo, as complexidades do cosmopolitismo vernacular das redes sul-sul ou as colaborações globais dos grupos indígenas, que são bastante conscientes do fato de estarem presos dentro desses conceitos hierárquicos e excludentes da modernidade. Essa abordagem é utilizada por Stuart Hall em sua argumentação sobre o "processo democrático agnóstico":

Nós testemunhamos a situação das comunidades que não são, simplesmente, isoladas ou formadas por indivíduos atomísticos, nem são comunidades singulares, separadas e bem delimitadas. Nós estamos naquele espaço aberto que requer um tipo de cosmopolitismo vernacular, isto é, um cosmopolitismo consciente das limitações de qualquer cultura ou qualquer identidade e radicalmente consciente de sua insuficiência para governar uma sociedade mais vasta, mas que, entretanto, não está preparado para desfazer as alegações referentes aos vestígios da diferença, que tornam suas vidas importantes. ${ }^{72}$

\footnotetext{
${ }^{64}$ MIGNOLO. The Many Faces of Cosmo-polis: Border Thinking and Critical Cosmopolitanism.

${ }^{65}$ POLLOCK. Cosmopolitan and Vernacular in History.

${ }^{66}$ Pollock também cita as mais diferenciadas histórias de vernaculização, na Europa e no sul da Ásia, como uma forma de advertência contra a reificação do "vernacular" ou do "cosmopolita."

${ }^{67}$ BHABHA; COMAROFF. Speaking of Postcoloniality, in the Continuous Present: A Conversation, p. 25.

${ }^{68}$ BHABHA. Unsatisfied: Notes on Vernacular Cosmopolitanism.

${ }^{69}$ GILROY. After Empire: Melancholia or Convivial Culture?

${ }^{70}$ HALL. Political Belonging in a World of Multiple Identities; BHABHA. Unsatisfied: Notes on Vernacular Cosmopolitanism.

${ }^{71}$ NYERS. Abject Cosmopolitanism: The Politics of Protection in the Anti-Deportation Movement, p. 1.089.

${ }^{72}$ HALL. Political Belonging in a World of Multiple Identities, p. 30.
} 
Acredito que o conceito de cosmopolitismo vernacular seja um instrumento útil nesta era globalizada e transnacional. ${ }^{73}$ A título de ilustração, vejamos como a narradora de Dubravka Ugresic vivencia uma modesta epifania em um salão de beleza, em Nova York, enquanto observa o proprietário vietnamita introduzindo uma mulher mexicana nos mistérios de seu negócio:

Os dois esticaram as pontas dos dedos um para o outro, tocando-se como dois alienígenas. Eu pensei sobre como as pessoas se escondem, como vinhas, formando passagens secretas por toda a superfície da terra. Sem parar. Incansavelmente. Eu pensei sobre como as pessoas migram, lançando-se de um lugar para outro, como areia; sobre como elas surgem repentinamente em um local, mensageiros misteriosos disfarçados, à primeira vista, de fomentadores de pequenas e insignificantes habilidades, como o tratamento das unhas. $\mathrm{Eu}$, igualmente holandesa e balcânica, as mulheres mexicanas e vietnamitas e esse homem vietnamita, todos nós acabamos nos encontrando no final de um dia nova-iorquino, envolvidos em um misterioso projeto, cujo significado não conseguiríamos decifrar. ${ }^{74}$

Chamar a atenção para a importância de se reconhecer os vários cosmopolitismos intranacionais - que conectam cada lugar a relações internacionais mais amplas - é algo realizado frequentemente, nas mais variadas formas, pelos escritores de nosso meio.

\begin{abstract}
A B S TR A C T
The concept of the relatively new term "vernacular cosmopolitanisms" acknowledges global contexts and responsibilities at the same time that it recognizes that these are always rooted in and permeated by local concerns that include competing minority groups within the nation. This paper examines the term "European" as a way to unpack revisionist debates in cosmopolitanism -specifically, in relation to "vernacular cosmopolitanisms", which is a way of including "subaltern cosmopolitanisms" by disaggregating cosmopolitanism in ways that echo Stuart Hall's notion of an "agnostic democratic process." The paradox of the phrase reflects the double movement of these debates: in Homi Bhabha's coinage of the term, the vernacular "native" or "domestic" is always in a dialogic relation with the globalcosmopolitan "action at a distance." I explore this dynamic by focusing on the discrepant meanings of "European" and associated terms. My central argument in this paper is that "European"
\end{abstract}

\footnotetext{
${ }^{73}$ Conferir também o trabalho de Shuh-mei Shi, que distingue entre as versões do cosmopolitismo vernacular e metropolitano, ou seja, o primeiro desafia o elitismo do segundo e opera, tanto globalmente quanto intranacionalmente, em países que são vistos como marginalizados (SHIH. Visuality and Identity: Sinphone Articulations across the Pacific, p. 170.). O trabalho de Shih focaliza, por exemplo, a Tailândia. ${ }^{74}$ UGRESIC. Nobody's Home: Essays, p. 158.
} 
and the "West" are terms that need to be deconstructed so that they can no longer be invoked as self-evidently heuristic categories in post-colonial debates, for example, the "West and the rest." The new cosmopolitan debates provide avenues for recognizing the cultural heterogeneity of such geo-political entities as nation-states and the European Union. Recognizing the cosmopolitanism of subaltern groups facilitates this enterprise and helps to reinstate a "planetary" perspective.

\section{KEYWORDS}

Cosmopolitism, diaspora, Australia

\section{WORKS CITED}

APPADURAI, A. Modernity at Large: Cultural Dimensions of Globalization. Minneapolis: University of Minnesota Press, 1996.

APPADURAI, A. (Ed.). Globalization. Durham \& London: Duke University Press, 2001. APPIAH, A. K. Cosmopolitanism: Ethics in a World of Strangers. New York: Norton, 2006. APPIAH, A. K. The Case for Contamination. NY Times Sunday Magazine, 1 Jan. 2006a. BALIBAR E. A Plea for an Alter-Globalising Europe. European Alternatives, v. 1, n.1, p. 6-8, Summer 2007.

BANNERJI, H. The Dark Side of the Nation: Essays on Multiculturalism, Nationalism and Gender. Toronto: Canadian Scholars' Press, 2000.

BARTLETT, R. H. The Mabo Decision. Sydney: Butterworths, 1993.

BECK, U. The Cosmopolitan Manifesto. New Statesman, v. 127, p. 4.377, 1998.

BECK, U. The Cosmopolitan Society and Its Enemies. Theory, Culture EF Society, v. 19, n. 1-20, p. 17-44, 2002.

BESMERES, M.; WIERZBICKA, A. (Ed.). Translating Lives: Living within Two Languages and Cultures. St. Lucia: The University of Queensland Press, 2007

BHABHA, H. Unsatisfied: Notes on Vernacular Cosmopolitanism. In: . Text and Narration: Cross-Disciplinary Essays on Cultural and National Identities. Ed. L. GarcíaMoreno \& P. C. Pfeiffer, Columbia, SC: Camden House Press, 1996. p. 191-207.

BHABHA, H.; COMAROFF, John. Speaking of Postcoloniality, in the Continuous Present: A Conversation. In: GOLDBERG, D. T.; QUAYSON, A. (Ed.). Relocating Postcolonialism. Oxford: Blackwell, 2002. p. 15-46.

BIDDLE, J. Breasts, Bodies, Canvas: Central Desert Arts as Experience. Sydney: The University of New South Wales Press, 2007.

BONNETT, A. The Idea of the West: Culture, Politics and History. New York: Palgrave Macmillan, 2004.

BRAH, A. Cartographies of Diaspora: Contesting Identities. London: Routledge, 1996. BRAND, D. Bread Out of Stone. Toronto: Coach House, 1994.

BRECKENRIDGE, C. et al. (Ed.). Cosmopolitanism. Durham: Duke, 2002. 
BRENNAN, T. Cosmopolitanism and Internationalism. New Left Review 7, Jan./Feb. 2001. BRENNAN, T. The Transmission of Affect. Ithaca/London: Cornell UP, 2004.

BROWN, M. Who Owns Native Culture? Cambridge: Harvard University Press, 2003. BURUMA, I.; MARGALIT, A. Occidentalism: The West in the Eyes of its Enemies. New York: Penguin, 2004.

CASTLES, S. The Racisms of Globalization. In: VASTA, E.; CASTLES, S. (Ed.). The Teeth Are Smiling: The Persistence of Racism in Multicultural Australia. Sydney: Allen \& Unwin, 1996. p. 30-110.

CHAKRABARTY, D. Provincializing Europe: Postcolonial Thought and Historical Difference. Princeton: Princeton University Press, 2000.

CHEAH, P.; ROBBIN, B. (Ed.). Cosmopolitics: Thinking Freely Beyond the Nation. Minneapolis: University of Minnesota Press, 1998.

CHEAH, P.; ROBBIN, B. Cosmopolitanism. Theory, Culture ES Society, v. 23, n. 2-3, p. 486-496, 2006.

CHOW, R. The Protestant Ethnic and the Spirit of Capitalism. New York: Columbia University Press, 2002.

COLEMAN, D. White Civility: The Literary Project of English Canada, Toronto: University of Toronto Press, 2006.

CORONIL, F. Beyond Occidentalism: Toward Nonimperial Geohistorical Categories. Cultural Anthropology, v. 11, n.1, p. 51-87, Feb.1996.

DERRIDA, J. Cosmopolitanism and Forgiveness. Trans. Mark Dooley. New York: Routledge, 2002.

DRAKULIC, S. Café Europa: Life After Communism. London: Abacus, 1996.

DRIEDGER, L. (Ed.). Ethnic Canada: Identities and Inequalities. Toronto: Copp Clark Pitman, 1987.

GAONKAR, D. P. (Ed.). Alternative Modernities. Durham \& London: Duke University Press, 2001.

GELDER, K. Reading the Vampire. London: Routledge, 1994.

GILBERT, Helen; LO, Jacqueline. Performance and Cosmopolitics: Cross-cultural Transactions in Australasia. Houndmills, Basingstoke: Palgrave Macmillan, 2007.

GILROY, P. After Empire: Melancholia or Convivial Culture? London: Routledge, 2004. GILROY, P. Postcolonial Melancholia. New York: Columbia University Press, 2005.

GORDON, A.; NEWFIELD, C. (Ed.). Mapping Multiculturalism. Minneapolis: University of Minnesota Press, 1996.

GUNEW, S. Framing Marginality: Multicultural Literary Studies. Melbourne University Press, 1994.

GUNEW, S. Haunted Nation: The Colonial Dimensions of Multiculturalisms. London: Routledge, 2004.

GUNEW, S. Rethinking Whiteness. Special issue of Feminist Theory, v. 8, n. 2, p. 141-14, 2007. 
HALL, S. Political Belonging in a World of Multiple Identities. In: VERTOVEC, S.; COHEN, R. (Ed.). Conceiving Cosmopolitanism: Theory, Context, and Practice. Oxford: Oxford University Press, 2002. p. 25-31.

HOFFMAN, E. The New Nomads. In: ACIMAN, A. (Ed.). Letters in Transit: Reflections on Exile, Identity, Language, and Loss. New York: NY Public Library, 1999. p. 35-63.

KOSTASH, M. Eurocentricity: Notes on Metaphors of Place. In: HRYNIUK, S. (Ed.). Twenty Years of Multiculturalism. Manitoba; St. John's College Press, 1991. p. 166-186.

KOSTASH, M. Bloodlines: A Journey in Eastern Europe. Vancouver/Toronto: Douglas \& McIntyre, 1993.

KOSTOVA, E. The Historian. New York: Back Bay Books, 2005.

KÜRTI, L. Globalisation and the Discourse of Otherness in the New Eastern and Central Europe. In: MODOOD, T.; WERBNER, P. (Ed.). The Politics of Multiculturalism in the New Europe: Racism, Identity and Community. London: Zed Books, 1997. p. 261-267.

KYMLICKA, W. Multicultural Odysseys: Navigating the New International Politics of Diversity. Oxford: Oxford University Press, 2007.

LACLAU, E. Universalism, Particularism and the Question of Identity. In: ALCOFF, L. M.; MENDIETA, E. (Ed.). Identities: Race, Class, Gender, and Nationality. Oxford: Blackwell, 2003. p. 360-368.

LAWRENCE, B.; DUA, E. Decolonizing Antiracism. Social Justice, v. 32, n. 4, p. 120-143, 2005.

LAZARUS, N. The Fetish of "the West" in Postcolonial Theory. In: BARTOLOVICH, C.; LAZARUS, N. (Ed.). Marxism, Modernity and Postcolonial Studies. Cambridge: Cambridge University Press, 2002. p. 43-64.

LEE, S. Disappearing Moon Café. Vancouver: Douglas \& McIntyre, 1990.

LOPEZ, A. (Ed.). Postcolonial Whiteness: A Critical Reader in Race and Empire. NY: SUNY Press, 2003.

LORIGGIO, F. (Ed.). Social Pluralism: and Literary History: The Literature of the Italian Emigration. Ottawa: Guernica. 1996.

MANNE, R. Dead Europe: by Christos Tsiolkas. The Monthly, p. 51-53, Jun. 2005.

McLEAN, I. White Aborigines: Identity Politics in Australian Art. Melbourne: Cambridge University Press, 1998.

MIGNOLO, W. The Many Faces of Cosmo-polis: Border Thinking and Critical Cosmopolitanism. In: BRECKENRIDGE, C. et al. (Ed.). Cosmopolitanism. Durham: Duke, 2002. p.157-187.

MISHRA, V.; HODGE, R. What is Post(-)colonialism? In: WILLIAMS, P.; CHRISMAN, L. (Ed.). Colonial Discourse and Postcolonial Theory: A Reader. London: Harvester Wheatsheaf, 1993. p. 276-290.

MORETON-ROBINSON, A. (Ed.). Whitening Race: Essays in Social and Cultural Criticism. Canberra: Aboriginal Studies Press, 2004.

NAVA, M. Visceral Cosmopolitanism: Gender, Culture and the Normalisation of Difference. Oxford: Berg, 2007. 
NG, R. Sexism, Racism and Canadian Nationalis. In: GUNEW, S.; YEATMAN A. (Ed.). Feminism and The Politics of Difference. Sydney: Allen \& Unwin, 1993. p. 197-211.

NYERS, P. Abject Cosmopolitanism: the Politics of Protection in the Anti-deportation Movement. Third World Quarterly, v. 24, n. 6, p. 1.069-1.093, 2003.

PERRIN, C. (Ed.). In the Wake of Terra Nullius (Special Issue), Law, Text, Culture, v. 4, n.1, Autumn 1998.

POLLOCK, S. Cosmopolitan and Vernacular in History. In: BRECKENRIDGE, C. et al. (Ed.). Cosmopolitanism. Durham: Duke, 2002. p. 15-53.

RAM, K. Liberal Multiculturalism's "NESB Women”: A South Asian Post-colonial Feminist Perspective on the Liberal Impoverishment of "Difference". In: VASTA, E.; CASTLES, S. (Ed.). The Teeth Are Smiling: The Persistence of Racism in Multicultural Australia. Sydney: Allen \& Unwin, 1996.

SHELLEY, M. Frankenstein. Oxford: Oxford University Press, 1969.

SHIH, S. Visuality and Identity: Sinphone Articulations across the Pacific. Berkeley: University California Press, 2007.

SPIVAK, G. Three Women's Texts and a Critique of Imperialism. In: LEWIS, R.; MILLS, S. (Ed.). Feminist Postcolonial Theory: A Reader. Edinburgh: Edinburgh University Press, 2003. p. 306-323.

STEPHENSON, P. Cross-Cultural Alliances: Exploring Aboriginal/Asian Literary and Cultural Production. In: PENNY, Edwards; YUAN-FANG, Shen (Ed.). Lost in the Whitewash: Aboriginal-Chinese Encounters from Federation to Reconciliation. Canberra: Humanities Research Centre, ANU, 2003. p. 143-161.

STEPHENSON, P. The Outsiders Within: Telling Australia's Indigenous-Asian Story. Sydney: University of New South Wales Press, 2007.

TODOROV, T. The New World Disorder. Cambridge: Polity Press, 2005.

TOUFIC, Jalal. Kneeling Angel with Mountainous Wings (a.k.a. Toward a Title for a Gibran Watercolor Left Untitled). Discourse, v. 24, n. 1, 2002.

TSIOLKAS, C. Loaded. Sydney: Random House Vintage, 1995

TSIOLKAS, C. Dead Europe. Sydney: Vintage Books, 2005.

UGRESIC, D. Nobody's Home: Essays. London: Telegram, 2007.

VASTA, E.; CASTLES S. (Ed.). The Teeth Are Smiling: The Persistence of Racism in Multicultural Australia. Sydney: Allen \& Unwin, 1996.

VERTOVEC, S.; COHEN, R. (Ed.). Conceiving Cosmopolitanism: Theory, Context, and Practice. Oxford: Oxford University Press, 2000.

WIEGMAN, R. Whiteness Studies and the Paradox of Particularity. Boundary 2, v. 26, n. 3, p. 115-150, 1999. 